\title{
Optimization of the Drag Force of Planing Boat with Trim Control System Using Genetic Algorithm
}

\author{
Abdollah Sakaki ${ }^{1}$, Hassan Ghassemi ${ }^{1, *}$, Koorosh Aslansefat ${ }^{2}$, Mohsen Sadeghian $^{1}$ \\ ${ }^{1}$ Department of Maritime Engineering, Amirkabir University of Technology, Tehran, Iran \\ ${ }^{2}$ Department of Electrical Engineering, Universidade Nova de Lisboa, Lisbon, Portugal \\ *Corresponding author: gasemi@aut.ac.ir
}

\begin{abstract}
The control surface is an effective apparatus for improving the performance of planing boats and is considered an important element in the design of planing boats. Trim-tabs are placed at the transom to give better trim angle in order to diminish the resistance. In this paper, algorithm genetic (GA) is applied to find the trim, resistance and dearrise angle using Savitsky's formulas. The input data are all boat dimensions, including trim-tab data. The output results are trim angle, longitudinal center of gravity $(\mathrm{lcg})$ and deadrise angle $(\beta)$ and minimum resistance.
\end{abstract}

Keywords: control surface, trim-tab, drag force, genetic algorithm

Cite This Article: Abdollah Sakaki, Hassan Ghassemi, Koorosh Aslansefat, and Mohsen Sadeghian, "Optimization of the Drag Force of Planing Boat with Trim Control System Using Genetic Algorithm." American Journal of Mechanical Engineering, vol. 5, no. 4 (2017): 161-166. doi: 10.12691/ajme-5-4-8.

\section{Introduction}

The concept of planing boats was recognized in the late nineteenth century, the first practical application of the concept can be traced to the development of seaplane hulls during the beginning of the twentieth century. The planing boat form remains one of the most effective concepts for high-speed marine vehicles that are employed in commercial, military, and recreational activities. The design of planing boat is one of the most important issues in naval architect. Prediction of the forces acting on a planing boat is required for hull form design. Planing boats have different behaviors in different situations. Hence, predicting high-speed vessels performance in different conditions is of great importance. A planing boat is a hull which performs only by hydrodynamic forces which are the impact of water on the hull. A vessel is planing when the length Froude number $\mathrm{Fr}>1.2$ [1]. We can't set a clear line of demarcation between planing and nonplaning conditions just by referring to the Froude number. The weight of the vessel is mainly supported by hydrodynamic pressure loads, with buoyancy having less importance in planing condition. The hydrodynamic pressure both lifts the vessel and affects the trim angle.

The important study of planing boats took place in Davison Laboratory at Steven institute of technology by Savitsky [2]. The elemental hydrodynamic characteristics of prismatic planing surfaces are discussed and empirical planing equations are given which describe the lift, drag, wetted area, center of pressure, and porpoising stability limits of planing surfaces as a function of speed, trim angle, deadrise angle, and loading. These results are combined to formulate simple computational procedures to predict the horsepower requirements, running trim, draft, and porpoising stability of prismatic planing boats. Subsequent to these studies, several other studies were conducted like the experimental and theoretical study of Brown [3] on planing surfaces with trim-tabs. His experiments were made on a 10 degree deadrise prismatic planing surface over a range of speed both with and without full span and half span trim flaps fitted at the transom. The lift, drag and pitching moment characteristics are summarized in planing formula which account for the effect of transom flaps and include the flap hinge moments. A few years later, another paper was published by Savitsky and Brown [4] in which effects of controlling the trim-tabs was studied. Included are studies related to the pre-planing resistance of transom-stern hulls, the effectiveness of trim control flaps, the effect of bottom warp on planing efficiency, the influence of reentrant transom forms and the seakeeping of planing boats. From that time on, the study of trim control system became more popular and their usage in controlling the additional trim of planing boats became the focal point of other studies.

The resistance tests of a systematic series of U.S. Coast Guard planing boats were carried out by Metcalf et al, 2005 [5]. They presented trim angle and resistance of four models in various conditions including different displacements, various centers of gravity and etc. The results in this report are presented as model scale values due to the conceptual nature of the program. It must be noted that the curves of resistance per pound of displacement will be affected when scaled to some notional full-scale vessel. However, the trends will not vary, but may become less obvious. The effect of expanding to full-scale will result in a flatter curve, where the low speed hump becomes less pronounced and less curvature exists at high speed. 
Characteristics of a series of high speed hard chine planing boats have examined [6]. These models consisted step and step-less crafts. They also presented their experimental data. The data presented provide a foundation for studying the performance of modern high speed planing boats in calm water and waves as well as providing valuable design data.

Begovic \& Bertorello tried to study the effect of variation of deadrise angle and introduced four hulls. In three models, deadrise angle varied from the stern to the bow of craft. Their observation indicated the complex behavior of the wetted area and the stagnation line angle [7].The reported results can be a useful reference when dealing with pre-planing and planing boat form. They high light a speed range where the warping of hull bottom and the increased deadrise angles of the forward part of the hull do not significantly affect the hydrodynamic resistance and identify a relative speed range where they can be comparable to medium-deadrise mono-hedral. This conclusion encourages the scheduled research focused on seakeeping and dynamic instability evaluation of non mono-hedral forms, aimed at providing more complete reference for planing boat form design. They also showed that keel wetted length increases by an increase in the speed of the warped hulls, while it decreases in the prismatic body.

On the other hand, three different planing boats were introduced by Kim et al for improving the performance and seakeeping of the planing boats [8]. In this study, third model has favorable resistance and seakeeping performance among the three model ships. Its hull form will be optimized to improve its hydrodynamic performance in the near future. And, stern appendages may be effective for reducing its required power. For good seakeeping performance, the bow shape is to be designed as a wavepiercing type. Test research on the resistance performance of high-speed trimaran planing boat was considered as a subject of research. The resistance tests took into consideration several factors, including steps, chine and deadrise of different types of planing surface. Also, water splash beside the hulls under high speed was observed [9]. A model test was conducted to provide a systematic understanding of the effects that displacement and step location have on the performance of a stepped planing boat. Seven different step configurations were tested at three different displacements and over a range of four different speeds in calm water. Of all the configurations tested, the stepped hull configurations showed reduced resistance compared with the unstepped hull and the best height of the step for decreasing the resistance was achieved [10]. In the present paper, optimization of the performance of the planing boats on running trim and resistance is investigated. For this purpose, mathematical formulation of Savitsky's method and effects of trim-tab on forces and center of pressure are explained. Later, the procedure of Savitsky's modified method for planing boats equipped with trim-tabs is introduced in a code. After validating the code, using the algorithm genetic is employed to optimize the drag force of planing boat with trim-tab in specified trim angle. The proposed method is used to examine the performance of one planing boats which analyzed by Savitsky and Brown (1976). Finally, optimizing the drag force of planing boat with trim control system by using GA is studied.
Here, also additional research on planing craft carried out by other researchers. A very nice book of hydrodynamics on the high speed marine vehicles published by Faltinsen in 2005 [11]. Chapter 9 focused on the planing hull in calm and wave water. Parametric study of the effects of trim-tabs on running trim and resistance of planing hulls presented by Ghadimi et al [12]. Loni et al developed a computer program for mathematical investigation of stepped planing hull characteristics [13]. Multiobjective particle swarm optimization of a planing craft with uncertainty was presented by Knight et al [14].

During 2008 2016, a comprehensive research on the planing craft carried out by Ghassemi and his colleagues. They worked on various planing hull and tunnel hull using boundary element method (BEM) and CFD solvers. They have presented the hydrodynamics of the planing hull using BEM to find pressure drag, induced drag and many related to hydrodynamic characteristics $[15,16,17,18,19]$. Ghassabzadeh \& Ghassemi employed a NURBS to design the hull of tunnel ship [20-23]. Also, many numerical results on the planing hull carried out by CFD solver $[24,25,26]$.

\section{Problem Formulas}

As pointed out earlier, the best option for modeling a planing boat with trim-tab is the modified Savitsky's method. The process is the same as in original Savitsky's method with a few add-ons. This case is defined by a few variables that are related to the geometry of planing body and the trim-tab. Moreover, the design speed and mass of planing body are included. With these variables, the output will be the trim angle and total resistance.

The last three parameters related to the trim-tab are described in the next paragraphs. With these results, a preferable case study can be conducted to predict the best situations where a trim-tab can be used in a planing body. The first assumption is the fact that the planing body is in a steady state condition which implies there is no acceleration in any direction. Here, a trim-tab is added to the planing body. Two parameters of the total mass of planing body and length of the center of gravity (LCG) are different from the original Savitsky's method. In order to implement these two parameters, it is important to understand the geometry of a trim-tab as shown in Figure 1.

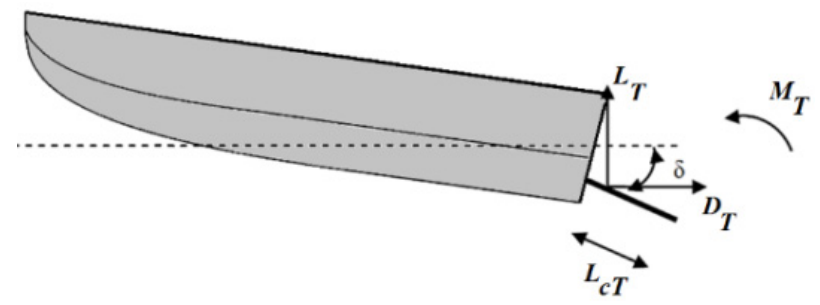

Figure 1. Trim-tab geometry

The Original Savitsky's method includes some steps which will be studied and executed. For getting the calculations started, first a trim angle must be guessed for the planing body and for terminating the calculations; the suitability of this guess should be assessed.

Subsequently, it is necessary to find the involved constants. These constants include the beam Froude 
number $F n_{B}$, and the lift coefficient $C_{L \beta}$. The lift coefficient is the parameter which gives enough force to lift the planing body. These two constants are calculated by equations (1) and (2).

$$
\begin{gathered}
F n_{B}=\frac{V}{\sqrt{g B}} \\
F_{L \beta}=M g, F_{L \beta}=0.5 \rho C_{L \beta} V^{2} B^{2}
\end{gathered}
$$

where $C_{L \beta}=\frac{M g}{0.5 \rho V^{2} B^{2}}$.

\section{Step 1:}

We can solve a nonlinear equation to find the mean wetted length-beam ratio $\lambda$ as follows,

$$
\begin{gathered}
F_{L \beta} \times l_{p}=M g \times l c g \\
0.5 \rho U^{2} B^{2} C_{L \beta}=\frac{l c g}{l_{p}} M g
\end{gathered}
$$

where $F_{L \beta}$ is lift force at dead rise of $\beta, l_{p}$ is center of lift force.

$$
\begin{gathered}
C_{L \beta}=C_{L 0}-0.0065 \beta C_{L 0}^{0.6} \\
C_{L 0}=\tau^{1.1}\left(0.012 \lambda^{0.5}+0.0055\left(\frac{\lambda^{2.5}}{F n_{B}^{2}}\right)\right) \\
l_{p}=C_{P} \lambda B, \\
C_{P}=0.75-\frac{1}{5.21\left(\frac{F n_{B}^{2}}{\lambda^{2}}\right)+2.39} \cdot \lambda=\frac{\left(L_{K}+L_{C}\right)}{2 B}
\end{gathered}
$$

where $C_{L 0}$ is the lift coefficient of planing plate at zero deadrise angle ( $\beta$ ). $\tau$ is the trim angle, and $\lambda$ is the non-dimensional mean wetted length-beam ratio. In the equation (7), first at each $F n_{B}$, the value $\tau$ is estimated, so there is only one unknown $\lambda$, obtain nonlinear equation to get $\lambda$.

Step 2:

We use the following formulas to calculate the total resistance. Friction drag coefficient $C_{F}$ can be determined by ITTC-57 equation given in equation (9). The friction resistance:

$$
D_{f}=0.5 \rho V^{2} S C_{F}
$$

where:

$$
\begin{gathered}
C_{F}=C_{F . I T T C}+\Delta C_{F} \\
C_{F . I T T C}=\frac{0.075}{(\log \log R n-2)^{2}} \cdot \Delta C_{F} \\
=\left[111(A H R . U)^{0.21}-404\right] C_{F . I T T C}^{2}
\end{gathered}
$$

with the following data:

$$
R n=\frac{U L_{k}}{v}, v=1.19 \times 10^{-6} \frac{\mathrm{m}^{2}}{\mathrm{~s}}, A H R=150 \times 10^{-6}
$$

where the Reynolds number is $R n$ and the kinematic viscosity of the water is $v$. After finding the Reynolds number and $S$, the frictional drag can be calculated.

$$
S=S_{1}+S_{2}
$$

$$
\begin{gathered}
S_{1}=\frac{\tan ^{2} \beta}{\sin \beta}\left(\frac{B^{2}}{4\left(\frac{1+z_{\max }}{V t}\right) \tau}\right), \\
S_{2}=\frac{B}{\cos \beta} L_{C} .
\end{gathered}
$$

In the calculation the wetted length $L_{K}$ and $L_{C}$ can be obtained as follows.

$$
L_{K}-L_{c}=x_{s}
$$

Thus

$$
\begin{aligned}
& L_{K}=\frac{1}{2}\left(2 \lambda B+x_{s}\right) \\
& L_{c}=\frac{1}{2}\left(2 \lambda B-x_{s}\right) .
\end{aligned}
$$

From $\frac{B}{2}=\frac{\pi}{2 \tan \beta} x_{s} \tau$, we know

$$
x_{s}=\frac{B \tan \beta}{\pi \tau}
$$

Thus

$$
L_{K}=\frac{1}{2}\left(2 \lambda B+\frac{B \tan \beta}{\pi \tau}\right) \cdot L_{C}=\frac{1}{2}\left(2 \lambda B-\frac{B \tan \beta}{\pi \tau}\right) .
$$

Now the friction resistance in equation (8) can be calculated and the lift induced resistance

$$
D_{P}=F_{L \beta} \times \tau=M g \times \tau .
$$

So the total resistance

$$
D_{\text {Total }}=D_{T}+D_{P}
$$

\section{Step 3:}

Find out the trim angle $\tau$ and the mean wetted length beam ratio $\lambda$ for the minimum resistance. After calculation minimum resistance, we got the trim angle. We can solve equation (4) together with (5)-(8) to find out the mean wetted length beam ratio $\lambda$. Then the distance from the transom stern to the center of action of the hydrodynamic force,

$$
l_{p}=\lambda B\left(0.75-\frac{1}{5.21\left(\frac{F n_{B}^{2}}{\lambda^{2}}\right)+2.39}\right)
$$

When $l_{p} \neq l c g$ the hydrodynamic force will cause a trim moment about $\mathrm{COG}$, and the trim moment must be counteracted by $M_{f}$ generated by the lift force on trim-tab. According to the equilibrium of moment about the center of gravity 


$$
M_{T}+F_{L \beta}\left(l_{p}-l c g\right)=0
$$

The lift force due to the trim-tab

$$
L=0.5 \rho U^{2} L_{c T} \pi \alpha B
$$

where the chord of the trim-tab is $L_{c T}, \alpha$ is the trim-tab angle. We know that there is air on the top of the trim, so the lift coefficient for the trim-tab is:

$$
C_{L}=0.5(2 \pi \alpha) \text {. }
$$

If we assumed the center of the lift force locates $x_{c p}=0.75 L_{c T}$ from the trailing edge. So the distance from the center of the lift to center of gravity is:

$$
x_{l}=\left(L_{c T}-0.75 L_{c T}\right)+l c g .
$$

Thus the trim-tab moment:

$$
M_{T}=F_{t a b} \times x_{l} .
$$

So we got the equations

$$
0.5 \rho U^{2} L_{c T} \pi \alpha B \times\left(0.25 L_{c T}+l c g\right)=M_{T} .
$$

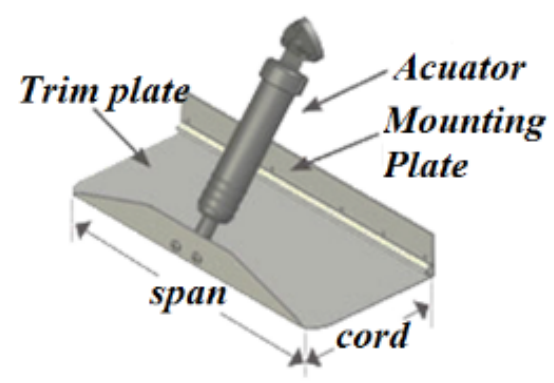

Figure 2. Trim-tab parameters
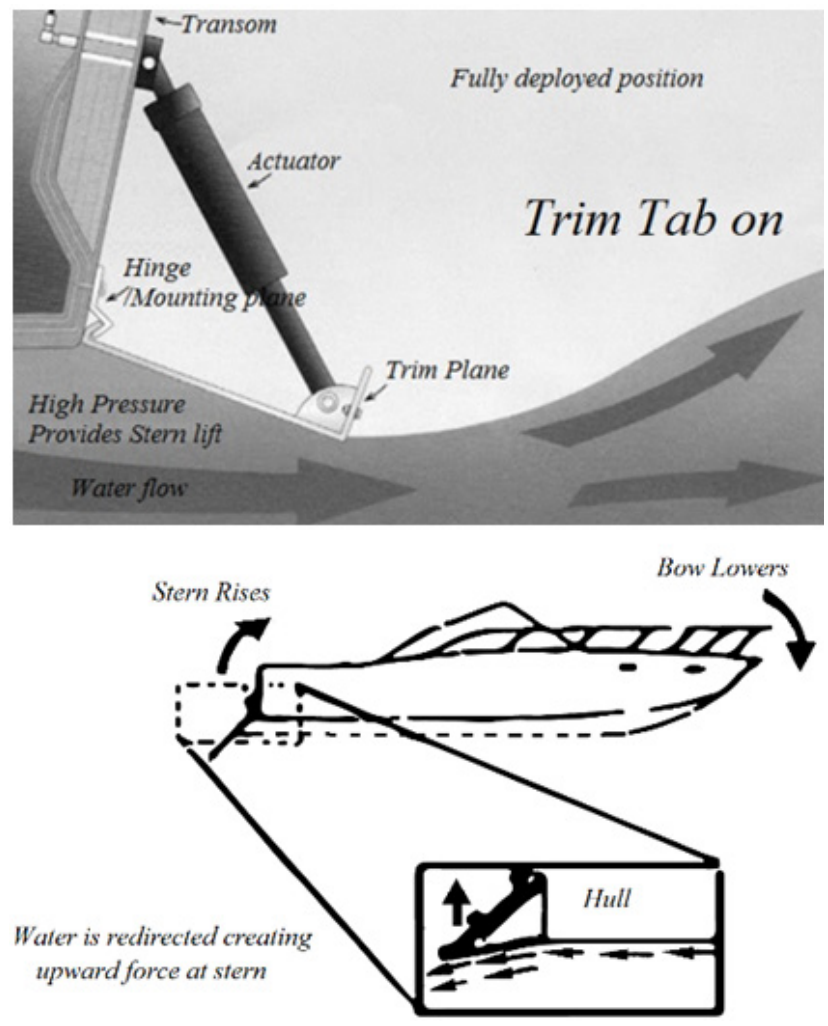

Figure 3. The effect of trim-tab on boat motion
We can prove that these two equations are equivalent, so we can use one of them to get the possible combination of trim-tab length $L_{c T}$ (the chord of the trim-tab) and trimtab angle. The positive $\alpha$ is to get downward lift force on the trim-tab. Figure 2 illustrates the parameters of the trim-tab and Figure 3 shows the effect of trim-tab on craft motion.

\section{Results and Discussion}

The process of using these equations for the purpose of intended analyses has been automated by different MATLAB programs. In order to clarify the process clearly, a flowchart is provided in Figure 4.

The optimal design of trim control system for planing boat can be considered as a multi-objective problem. Evolutionary algorithms are in fact non-classical methods that do not fall into the trap of local minimums. One of the well-known methods is named GA, known as a method to find optimal solutions. In this approach, the input variables $\left(l c g, \beta\right.$ and $V_{n}$ ) are assumed as genotype and the output variables (trim and resistance) are considered as phenotype.

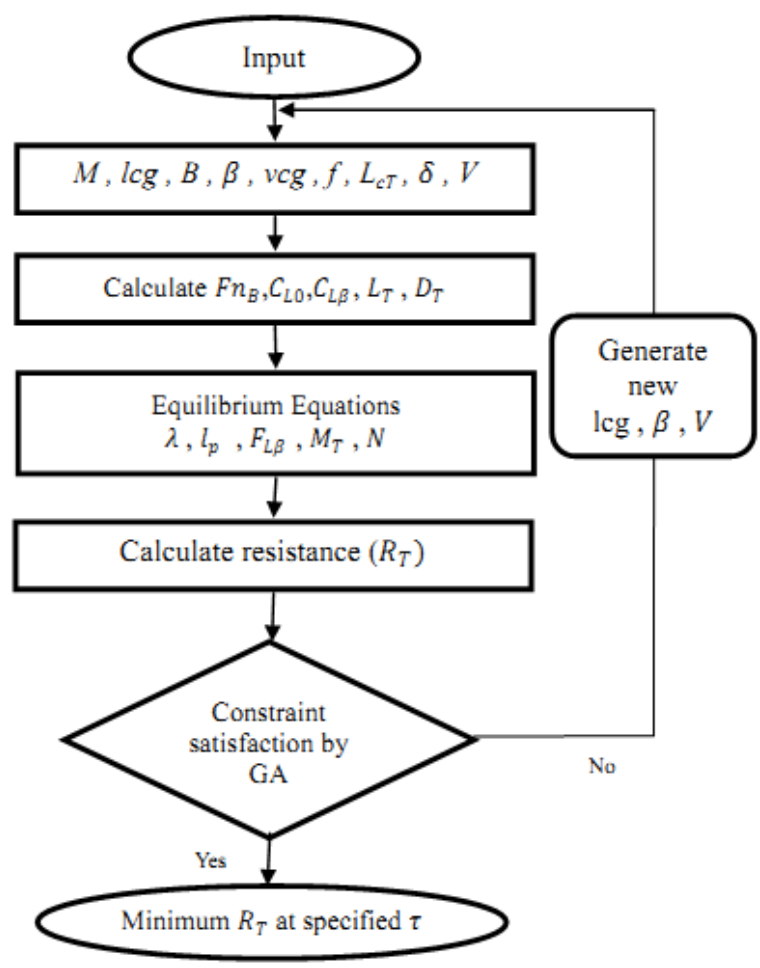

Figure 4. Flowchart of the computational process

Note that all input variables are generated by uniformly distributed pseudorandom numbers; lc $g$ with the bound of 5 to $10, \beta$ with the band of 0 to 20 and $V_{n}$ with the band of 30 to 80 . In each generation, selection functions pick the most valuable genes are chosen as the parents of the next generation, and then the crossing over procedure is performed on them. Among these, the random genes

$$
J\left(V_{n}, l c g, \beta\right)=\omega_{1} \frac{R E}{R R E}+\omega_{2} \frac{T R}{R T R}
$$

where $R R E$, and $R T R$ are the requirements of the resistance, and the trim, respectively. Depending on the 
practice situation, the importance of each $R E$, and $T R$ can be weighted via $\omega_{1}$, and $\omega_{2}$, respectively. The introduced weight can be chosen differently depending on the application. For example, if in the hypothetical planing boat, resistance reduction is the most important issue and is added to the population as mutation functions and this procedure is repeated until ultimate criteria are established [27]. Different conditions can be set to stop the problem. In this paper, the condition was to reach to the maximum number of iterations which is set to 500 .

Any evolutionary optimization algorithm needs to be configured by settings. In optimization as mentioned above, population size is considered 40 ; the percentage of mutation; crossover and recombination are set $35 \%, 50 \%$, and $15 \%$ respectively. Single point crossing over is used for crossover function and mutations generated by a random function.

In the trim control system's design problem, trim and resistance straightly depends on some design parameters ( $\beta$ and $l c g$ ) and increasing $\beta$ or $l c g$ leads to increasing the trim value. To make a trade-off between optimization of resistance, and trim, the weighted-sum cost function can be used as RE has priority over TR, the weights of cost function $J\left(V_{n} \cdot \operatorname{lcg} \cdot \beta\right)$ should be considered as $\omega_{1}>\omega_{2}$.

As a result of GA optimization, the optimal value of " $\beta$ ", "lcg" and " $V_{n}$ " can be achieved. In other words, the aim of optimization problem can be written as follows:

$$
\left(V_{n}, l c g, \beta\right)=\arg \min \left(V_{n}, l c g, \beta\right) .
$$

For validating the results of the written program, the case in Savitsky and Brown's paper (1976) is studied in this section. This case is pertinent to a planing body possessing a trim-tab whose characteristics are described in Table 1. This case is revisited again as the second case being parametrically studied in the current paper.

As seen in Table 1, the span of trim-tab is exactly equal to the beam of planing boat which implies that trim-tab uses the whole beam. This type of trim-tab is called full span trim-tab and the cord of trim-tab is equal 1. Results of this case study are shown in Table 2 and compared against the original results of Savitsky's paper.

Table 1. Main dimensions of the planing boat

\begin{tabular}{lc}
\hline Parameter & Value \\
\hline Beam [m] & 7.32 \\
lcg from stern [m] & 10.675 \\
vcg [m] & 0.5 \\
Deadrise angle $\beta[\mathrm{deg}]$ & 15 \\
$\mathrm{f}[\mathrm{m}]$ & 0.6 \\
$\varepsilon[\mathrm{deg}]$ & 0 \\
Design speed [knots] & 25.4 \\
Flap chord [m] & 0.305 \\
Span [m] & 7.32 \\
Flap Deflection $\delta$ deg] & 5 \\
\hline
\end{tabular}

\begin{tabular}{lcc}
\hline \multicolumn{3}{c}{ Table 2. Comparison of results } \\
\hline Parameter & Savitsky's results & Present calculated \\
\hline Trim angle $[\mathrm{deg}]$ & 2.9 & 2.97 \\
Total resistance $[\mathrm{N}]$ & 72061 & 73151 \\
\hline
\end{tabular}

Table 3. Comparison of the results

\begin{tabular}{lccc}
\hline Parameter & $\begin{array}{c}\text { Savitsky \& } \\
\text { Brown (1976) }\end{array}$ & $\begin{array}{c}\text { GA } \\
\text { Optim. }\end{array}$ & $\begin{array}{c}\text { GA Optim. } \\
\text { with various } \boldsymbol{\beta}\end{array}$ \\
\hline Total Resis. N] & 72061 & 64072.69 & 68883.4 \\
Trim angle [deg] & 2.9 & 1.924 & 2.44 \\
Velocity [m/s] & 25.4 & 25.4 & 25.4 \\
lcg [m] & 10.675 & $12.42 \mathrm{~m}$ & $11.8 \mathrm{~m}$ \\
Deadrise angle [deg] & 15 & 15 & 16.5 \\
\hline
\end{tabular}

By looking at Table 3, it can be understood that results are quite close. The trim angle has a $2.41 \%$ error, while the total resistance has a $1.51 \%$ error. These errors are attributed to the number of used decimals and can be quite natural. Some important parameters that can affect the performance of a planing boat with a trim-tab are boat velocity, longitudinal center of gravity and deadrise angle. After optimizing via GA, the optimal resistance for the case of Savitsky and Brown (1976) is $\mathrm{R}=67072.69$ at specified trim angle 1.924 degree.

\section{Conclusions}

In this paper, the goal was optimization of planing boats base on Savitsky's equations using GA. The GA method uses three variables $V_{n}, l c g, \beta$ which effect total resistance of boat. In this study, case of Savitsky and Brown were optimized by only changing the $l c g$ variables. The results show the decrease of total resistance of that boat in a specified trim angle. Therefore, changing the $l c g$ variables eventuate the change in trim angle which lessens the total resistance.

The performance of planing boat with variable deadrise angles was considered. Optimization by changing the deadrise showed that the total resistance decreased in different deadrise angles. This method can be used as a proper optimization tool for designing the planing boats.

\section{Nomenclatures}

$\begin{array}{ll}\text { Parameter } \quad \text { Definition } \\ M & \text { Displacement } \\ F_{L \beta} & \text { Hydrodynamic force } \\ \beta & \text { Deadrise angle } \\ \rho & \text { Density of water } \\ C_{L 0} & C_{L \beta} \text { at zero deadrise angle } \\ C_{L \beta} & \text { Lift coefficient } \\ C_{P} & \text { Pressure coefficient } \\ C_{F} & \text { Frictional drag coefficient } \\ C_{L} & \text { Lift coefficient of trim-tab } \\ \lambda & \text { Mean wetted length-to-beam ratio } \\ l_{p} & \text { Longitudinal position of the center of pressure } \\ & \text { measured along the keel from the transom stern } \\ L_{K} & \text { Keel wetted length } \\ L_{C} & \text { Chine wetted length } \\ L_{T} & \text { Lift of trim-tab } \\ D_{T} & \text { Drag of trim-tab } \\ M_{T} & \text { Moment of trim-tab } \\ L_{C T} & \text { Trim-tab chord } \\ \delta & \text { Trim-tab angle }\end{array}$


$\tau \quad$ Trim angle of planing surface

$F n_{B} \quad$ Beam Froude number

$R n \quad$ Reynolds number

$B \quad$ Breadth of the Boat

$V \quad$ Boat velocity

$g \quad$ Gravitational acceleration

$D_{f} \quad$ Frictional resistance

$S \quad$ Surface of the boat

$v \quad$ Kinematic viscosity of the water

$\alpha \quad$ Trim-tab angle

$x_{c p} \quad$ Center of lift force of trim-tab

$x_{l} \quad$ Distance from the center of lift force of trim-tab to center of gravity

lcg Longitudinal center of gravity

$v c g \quad$ Vertical center of gravity

\section{References}

[1] Benford H. Naval Architecture for non-naval architects, book. SNAME, 1991.

[2] Savitsky D. Hydrodynamic design of Planing boats. Marine Technology 1, 1964, 71-95.

[3] Brown P. An experimental and theoretical study of planing surfaces with trim flaps. Davison Laboratory report SIT-DL-711463, Stevens's institute of Technology, 1971, Hoboken, NJ, USA.

[4] Savitsky D. Brown P. Procedures for hydrodynamic evaluation of planing boats in smooth and rough water. Marine Technology 13, 1976, 381-400.

[5] Metcalf B J, Faul L, Bumiller E, Slutsky J. Resistance tests of a systematic series of U.S. Coast Guard planing boats. Cadrerock Division, Naval Surface Warfare Centre, Report No. NSWCD-50TR-2005.

[6] Taunton D J, Hudson D A, Shenoi R A. Characteristics of a series of high-speed hard chine planing boats-part 1: performance in calm water. Int. J of Small Craft Tech, 152. 2010, 55-75.

[7] Begovic E, Bertorllo C., Resistance assessment of warped hull form, Ocean Engineering, 56, 2012, 28-42.

[8] Kim DJ, Kim SY, You YJ, Rhee KP, Kim SH, Kim YG. Design of high-speed planing boats for the improvement of resistance and seakeeping performance. Int. J. of Naval Arch. and Ocean Eng., 5, 2013, 161-177.

[9] Ma D W, Sun H, Zou J, Yang H. Test research on the resistance performance of high-speed trimaran planing boat. Polish Maritime Research, 20, 2013, 45-51.

[10] Lee E, Pavkov M, Leigh M. The systematic variation of step configuration and displacement for a double step planing craft, $\mathrm{J}$ of Ship Production and Design, 30(2), 2014, 89-97.

[11] Faltinsen, O.M., Hydrodynamics of High-Speed Marine Vehicles (Chapter 9), 2005, Cambridge University Press, New York.
[12] Ghadimi, P, Loni A, Nowruzi H, Dashtimanesh A, and Tavakoli S, Parametric study of the effects of trim-tabs on running trim and resistance of planing hulls, Advanced Shipping and Ocean Engineering, 3(1), 2014, 1-12.

[13] Loni, A., Ghadimi, P., Nowruzi, H. and Dashtimanesh, A., Developing a computer program for mathematical investigation of stepped planing hull characteristics, Int. J of Physical Research, 1(2), 2013, 34-47.

[14] Knight, J.T., Zahradka, F.T., Singer, D.J. and Collette, M.D., Multiobjective particle swarm optimization of a planing craft with uncertainty, J of Ship Production and Design, 30(4), 2014, 194-200.

[15] Ghassemi H. Ghiasi M., A combined method for the hydrodynamic characteristics of planing crafts, Ocean Engineering 35 (3), 2008, 310-322.

[16] Ghassemi H, Kohansal AR, Ghiassi M. Numerical prediction of induced pressure and lift of the planing surfaces, China Ocean Engineering 23 (2), 2009, 221-232.

[17] Kohansal AR. Ghassemi H., A numerical modeling of hydrodynamic characteristics of various planing hull forms, Ocean Engineering 37 (5), 2010, 498-510.

[18] Ghassemi H, Kohansal AR, Hydrodynamic analysis of nonplaning and planing hulls by BEM, Scientia Iranica. Transaction B, Mechanical Engineering, 17(1), 2010, 41.

[19] Kohansal AR, Ghassemi H, Ghiasi M, Hydrodynamic characteristics of high speed planing hulls, including trim effects, Turkish J1 of Eng. and Environmental Sciences 34(3), 2011, 155-170.

[20] Ghassabzadeh M, Ghassemi H, Automatic generation of the planing tunnel high speed craft hull form, J. Marine Sci. Appl., 2012, 11, 453-461.

[21] Ghassabzadeh M, Ghassemi H, Numerical hydrodynamic of multihull tunnel vessel, Open J of Fluid Dynamics 3(3), 2013.

[22] Ghassabzadeh M, Ghassemi H, An innovative method for parametric design of planing tunnel vessel hull form, Ocean Engineering 60, 2013, 14-27.

[23] Ghassabzadeh M, Ghassemi H, Determining of the hydrodynamic forces on the multi-hull tunnel vessel in steady motion, $J$ of the Brazilian Society of Mech. Sci \& Eng., 2014, 36(4), 697-708.

[24] Ghassemi H, Kamarlouei M, Veysi STG, A hydrodynamic methodology and CFD analysis for performance prediction of stepped planing hulls, Polish Maritime Research 22(2), 2015, 23-31.

[25] Veysi STG, Bakhtiari M, Ghassemi H, Ghiasi M, Toward numerical modeling of the stepped and non-stepped planing hull, Journal of the Brazilian Society of Mechanical Sciences and Engineering, 2015, 37(6), 1635-1645.

[26] Bakhtiari M, Veysi STG, Ghassemi H, Numerical modeling of the stepped planing hull in calm water, Int. J of Eng.-Trans B: Applications, 29 (2), 2016.

[27] Floreano D, Mattiussi C. Bio-Inspired Artificial Intelligence Theories, Methods, and Technologies, London, England: MIT, 2008. 